\title{
Refinements in the Design of the Ares V Cargo Launch Vehicle for NASA's Exploration Strategy
}

\author{
Steve Creech, Integration Manager, Ares V \\ Ares Projects Office \\ Marshall Space Flight Center \\ Huntsville, AL 35812
}

\begin{abstract}
NASA is developing a new launch vehicle fleet to fulfill the national goals of replacing the shuttle fleet, completing the International Space Station (ISS), and exploring the Moon on the way to eventual exploration of Mars and beyond. Programmatic and technical decisions during early architecture studies and subsequent design activities were focused on safe, reliable operationally efficient vehicles that could support a sustainable exploration program. A pair of launch vehicles was selected to support those goals the Ares I crew launch vehicle and the Ares V cargo launch vehicle. They will be the first new humanrated launch vehicles developed by NASA in more than 30 years (Figure 1). Ares I will be the first to fly, beginning space station ferry operations no later than 2015. It will be able to carry up to six astronauts to ISS or support up to four astronauts for expeditions to the moon. Ares V is scheduled to be operational in the 2020 timeframe and will provide the propulsion systems and payload to truly extend human exploration beyond low-Earth orbit. (LEO).
\end{abstract}

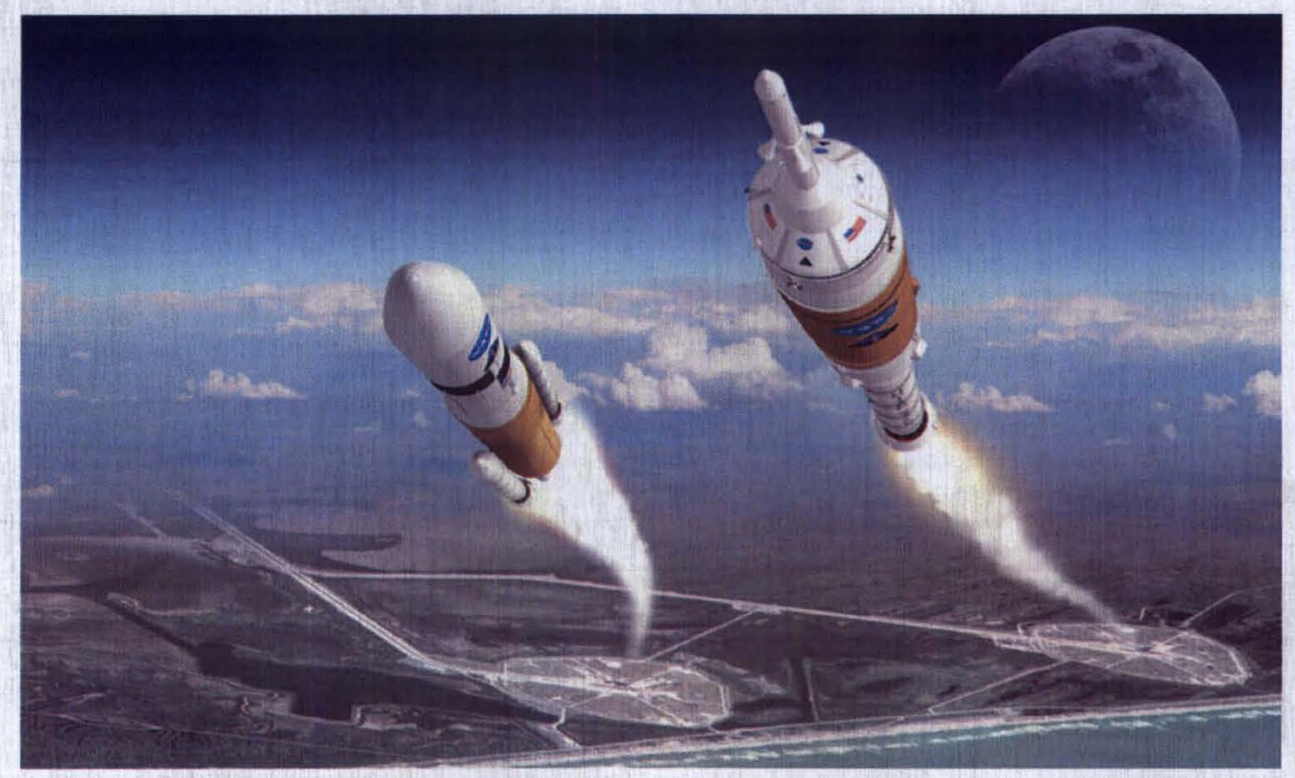

Figure 1. The Ares V Cargo Launch Vehicle (left) and Ares I Crew Launch Vehicle (right) will form the backbone of America's new space fleet. (NASA artist's concept)

The Ares V will be 361.9 feet tall. It will deliver 128.8 metric tons (283,913 pounds) to LEO or 54.2 metric tons (119,521 pounds) to trans-lunar injection. The reference lunar mission would begin by launching the Ares V, carrying the lunar lander, into orbit to be checked out before launching the crew aboard an Ares I. The Ares V first stage propulsion system consists of a core stage powered by five commercial liquid hydrogen/liquid oxygen $\left(\mathrm{LH}_{2} / \mathrm{LOX}\right) \mathrm{RS}-68$ engines, flanked by two five-segment solid 
rocket boosters. Atop the core stage is the Earth departure stage (EDS), powered by a single J-2X upper stage engine, and a payload shroud enclosing the lunar lander. The EDS/lunar lander will go into a stable checkout orbit. The Ares I, carrying the Orion crew exploration vehicle, will follow the Ares V into orbit. The Ares I first stage consists of a single five-segment SRB. Once that stage is expended during launch, the upper stage, powered by a single J-2X, will ignite to take the Orion into orbit. The upper stage is then expended. After Orion docks with the EDS/lander, the J-2X will ignite a second time to begin a translunar injection (TLI) burn. The EDS would be expended following the TLI burn. The Orion and lunar lander perform the remainder of the mission, with Orion remaining in lunar orbit autonomously while the crew descends to the Moon in the lander. At the end of the surface stay, the crew returns to Orion in the lander ascent stage, which is then discarded. The crew returns to Earth in the Orion crew module for reentry and landing.

\section{Ares V Design Evolution}

The two-vehicle architecture emerged in 2005 during the Exploration Systems Architecture Study (ESAS) and was further refined during subsequent design trades. The ESAS called for the successor to the space shuttle to be composed of a new crew exploration vehicle launched by a crew launch vehicle derived in large part from existing space shuttle propulsion elements, including the reusable solid rocket motor (RSRM) and the space shuttle main engine (SSME). The desire for commonality led the study team to use the same propulsion elements for the cargo launch vehicle, as well as a 27.5 -foot diameter core stage, corresponding to the shuttle external tank and its existing manufacturing tooling. In NASA design studies that followed the final ESAS report, the Ares V configuration changed from a 4-segment reusable solid rocket booster first stage/RS-25 space shuttle main engine upper stage to a 5-segment booster first stage/J-2X upper stage engine. Although the Ares I and Ares V shared the same first stage booster and upper stage engine, follow-on engineering and business trade studies concluded that design development test and engineering costs could be reduced and out-year savings realized by using the commercially available, expendable RS-68 engine, shown in Figure 2.

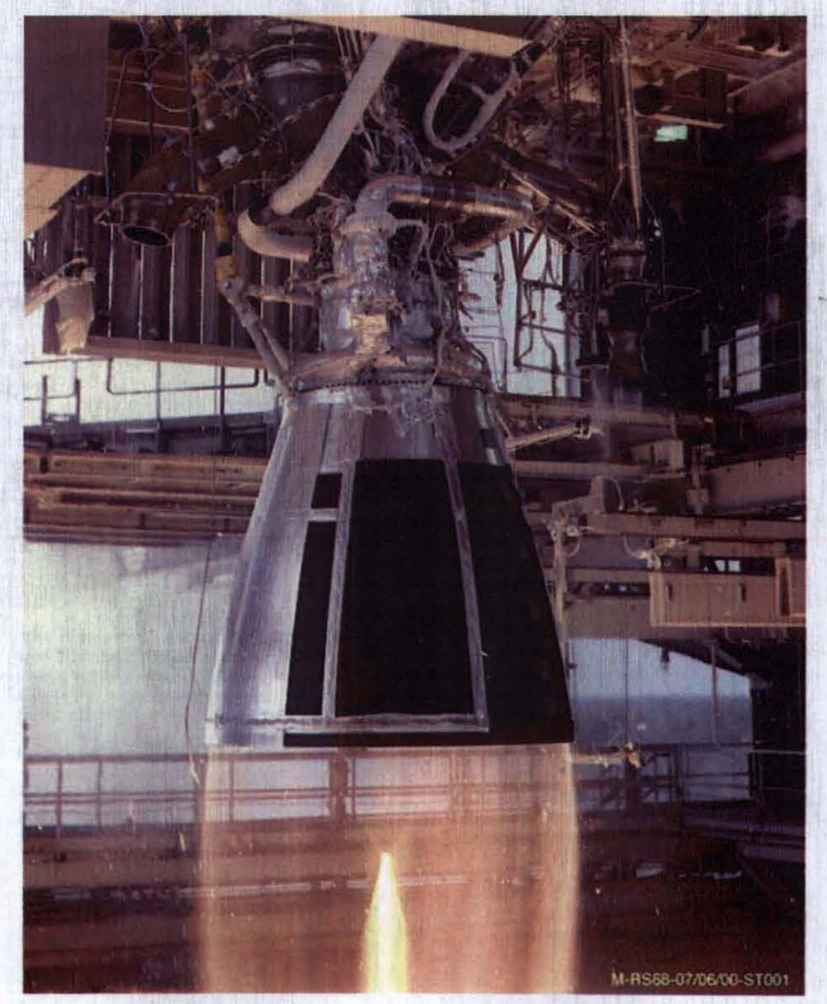

Figure 2. RS-68 during testing. 
Made by Pratt\&Whitney Rocketdyne (PWR), The RS-68 was developed for the U.S. Air Force Evolved Expendable Launch Vehicle program and flown on the Delta IV launch vehicle family. The RS68 is the most powerful $\mathrm{LOX}_{\mathrm{LH}}$ booster engine in existence, capable of producing 650,000 pounds of thrust at sea level. By comparison, the SSME can produce 420,000 pounds of thrust, though it operates at a higher efficiency. The ESAS had considered and rejected the RS- 68 because its lower specific impulse (Isp) and size were not compatible with the 27.5-foot core stage propellant tank and payload requirements for the Ares V. The ESAS had theorized that the high performance RS-25 might be redesigned as an expendable engine to reduce manufacturing cost by roughly half. However, analyses that followed showed that the RS-68, modified to meet NASA requirements, would cost significantly less than a modified SSME. This represents a major savings in recurring costs, especially because each Ares V mission will use five main engines at a rate of two missions annually over a decade. Analyses also showed that the cost, technical, schedule, and safety risks of redesigning the RS-25 were greater than the risk associated with scaling up the core stage to 33 feet in diameter to hold additional propellants for the less efficient RS-68 and make room for the larger engine. While RS-25 production had concluded, the RS-68 production line was gearing up for a goal of delivering 40 engines annually.

To meet NASA's needs, the RS-68 would need several changes, including both specific impulse and thrust. The Ares V application would also require a more robust RS-68 to prevent cracks in the turbomachinery blade as well as bearing and foreign object debris caused by the engine's gas generators. It required an ablative nozzle that could withstand 327 seconds of operation instead of the 250 seconds for a standard Air Force mission. Hardware and software changes were also needed to reduce the presence of free hydrogen around the launch pad during engine start, particularly as the core stage would use five engines to the Delta IV's three engines. The Ares V study group sought to reduce Ares V's use of helium because it is a nonrenewable and increasingly expensive resource. Some of the upgrades necessary for Ares V were already part of an Air Force upgrade program designated RS-68A. The Air Force was planning process and design changes that result in improved engine reliability and performance, while the NASA requirement required further performance improvement, as well as increased operability and safety.

\section{Development focuses on Core Stage Engine}

The Ares I is NASA's top priority because of the need to replace the space shuttle fleet, due to retire in 2010. Full-scale development work on Ares V was not scheduled to begin until 2012. However, initial seed money provided by Congress for the Ares V allowed NASA to begin early planning and design work largely focused on the core stage and the RS-68. That work included a benchmarking trip to Michoud Assembly Facility in May 2006. Discussions with other governmental agencies on developing a common engine to follow the RS-68A allowed participants to look for opportunities to identify existing hardware to support early risk reduction testing.

The Constellation Control Board approved the engine change in May 2006. In August 2006, following several months of informal discussion between NASA and other government customers, the NASA administrator directed the Core Stage Office at the Marshall Center to pursue development of one engine for both the Ares V and the Boeing Delta IV fleet. In September 2006, NASA and Air Force officials met to review engine upgrades planned or desired by both parties and discuss a partnering strategy for a common engine. In a memorandum of understanding, they agreed to a common engine approach that leveraged the work of both organizations. The Air Force benefited by additional risk reduction testing and NASA performance upgrades. NASA would benefit from reduced development costs and the chance to obtain early flight data on Delta IV missions. In October 2006, the Constellation Control board granted authority to proceed with the RS-68B engine variant.

To speed work and focus on the engine, NASA's Core Stage Element Office held an Upgrade Requirements Review (URR) in October 2006, recognizing that NASA was not in control of all the 
engine requirements included in the RS-68B because it was to be an evolution of the RS-68A, managed and operated by another customer. The URR did cover NASA's proposed changed to the turbopumps to reduce helium consumption, system modification to reduce free hydrogen, and an increase in the exhaust nozzle's burn duration capability. Seed money also supported a series of subscale tests in 2006 and 2007 that helped establish the optimum element density for both the RS-68 and the J-2X main injectors. It also allowed fabrication of hardware for the helium spin start, which would reduce free hydrogen accumulation around the launch pad. The free hydrogen issue was quantified by PWR with a detailed computational fluid dynamics analysis of the stage at lift-off. Operation of the core stage was evaluated and documented with the baselined Operations Concept for Core Stage document, and the Austin Company completed a study planning the hardware flow and facilities upgrades at Michoud Assembly facility. The element developed a candidate core stage design approach, documented in the Core Stage Design Analysis Cycle) Design Definition Document, submitted to the MSFC Advanced Concepts Office for further work. In order to define the roles with its Defense Department partners, the element drafted an Interagency Agreement for engine upgrade work, which was pending signatures at the time the seed money was expended. With the end of that seed money, engine work ended in May 2007.

Internal design work by the Advanced Concepts Office at Marshall Center continued. In a study of options to improve the Ares V TLI payload, an option consisting of an HTPB propellant, composite motor casing, and new exhaust nozzle for the RSRB provided an additional 4.5 metric tons. It bested five other options: core stage composite unpressurized structure, regeneratively cooled RS-68 nozzle, composite RSRB, a sixth RS-68, and an all composite EDS. The Advanced Concepts office also conducted a study to determine if a tangent ogive or single angle nosecone would yield better performance than the reference biconic angle nosecone for the reference Ares V concept. In an analysis that included updated aerodynamics, shroud masses, and resulting performance gains and losses, the reference biconic shroud exhibited the highest injected payload mass to LEO and was easier to fabricate compared to ogive.

Advanced Concepts also evaluated five EDS/shroud configurations that included EDS and shroud diameters of 8.4 and 10 meters and cylindrical heights ranging from 7.31 to 10 meters. The options . provided less TLI payload than the reference EDS diameter of 8.4 meters and 10-meter-long shroud. Overall, studies to date suggest that the Ares V lift requirement needs to be better understood and defined. Performance enhancements have been identified that cover the range of anticipated performance needs based on the CARD requirements and Lunar Architecture Team results. The biconic nosecone was confirmed as the best configuration. A common 10-meter EDS diameter and payload shroud diameter also is optimal for the mission.

\section{Conclusion}

NASA's Ares Projects Office is designing the Ares V to deliver large-scale hardware and supplies to space to support the agency's Global Exploration Strategy with a permanent lunar outpost and missions beyond. Work continues to refine the Ares V design, while progress on the 5-segment RSRB and the J-2X Upper stage engine for Ares I also benefits the Ares V. This work will ensure that Ares V will be ready when needed to carry human exploration into the solar system. 


\section{Refinements in the}

Design of the Ares V Cargo Launch Vehicle for NASA's Exploration Strategy AIAA Joint Propulsion Conference, July 20-23, 2008

Steve Creech Integration Manager, Ares V Ares Projects Office Marshall Space Flight Center, NASA

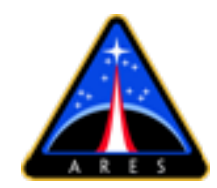




\section{Introduction}

- The NASA Ares Projects Office is developing the launch vehicles to move the United States and humanity beyond low earth orbit

- Ares I is a crewed vehicle, and Ares $V$ is a heavy lift vehicle being designed to place cargo on the Moon

- This is a work-in-progress, and we are presenting a "snapshot" of the ongoing effort

- The Ares V vehicle will be considered a national asset, opening new worlds and creating unmatched opportunities for human exploration, science, national security, and space business

- Our goal today is to introduce you to the Ares V vehicle

- Mission and Vehicle Overview

- Performance Description 


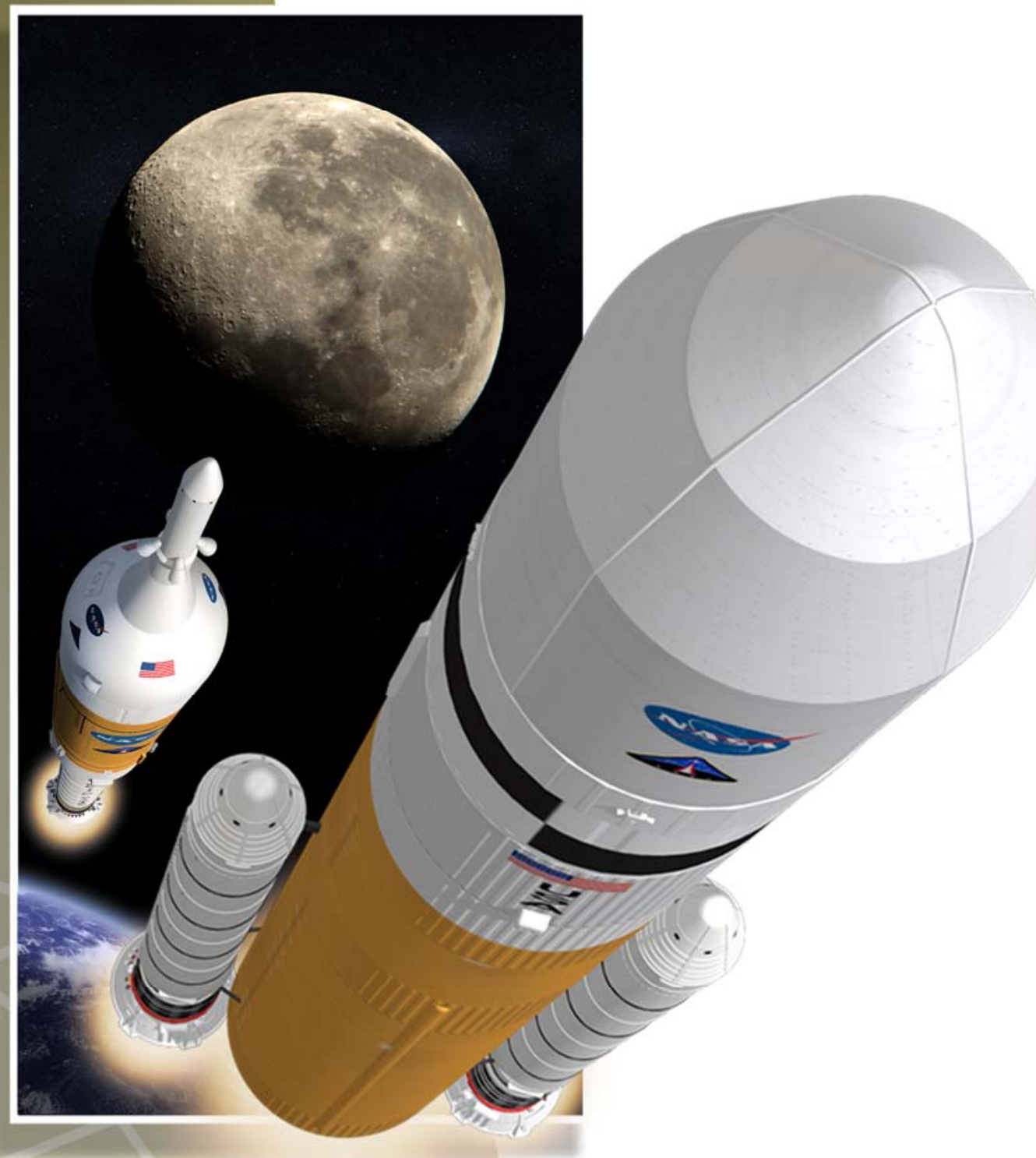

\section{Ares V Mission and Vehicle Overview}




\section{Building on a Foundation of Proven Technologies Launch Vehicle Comparisons}

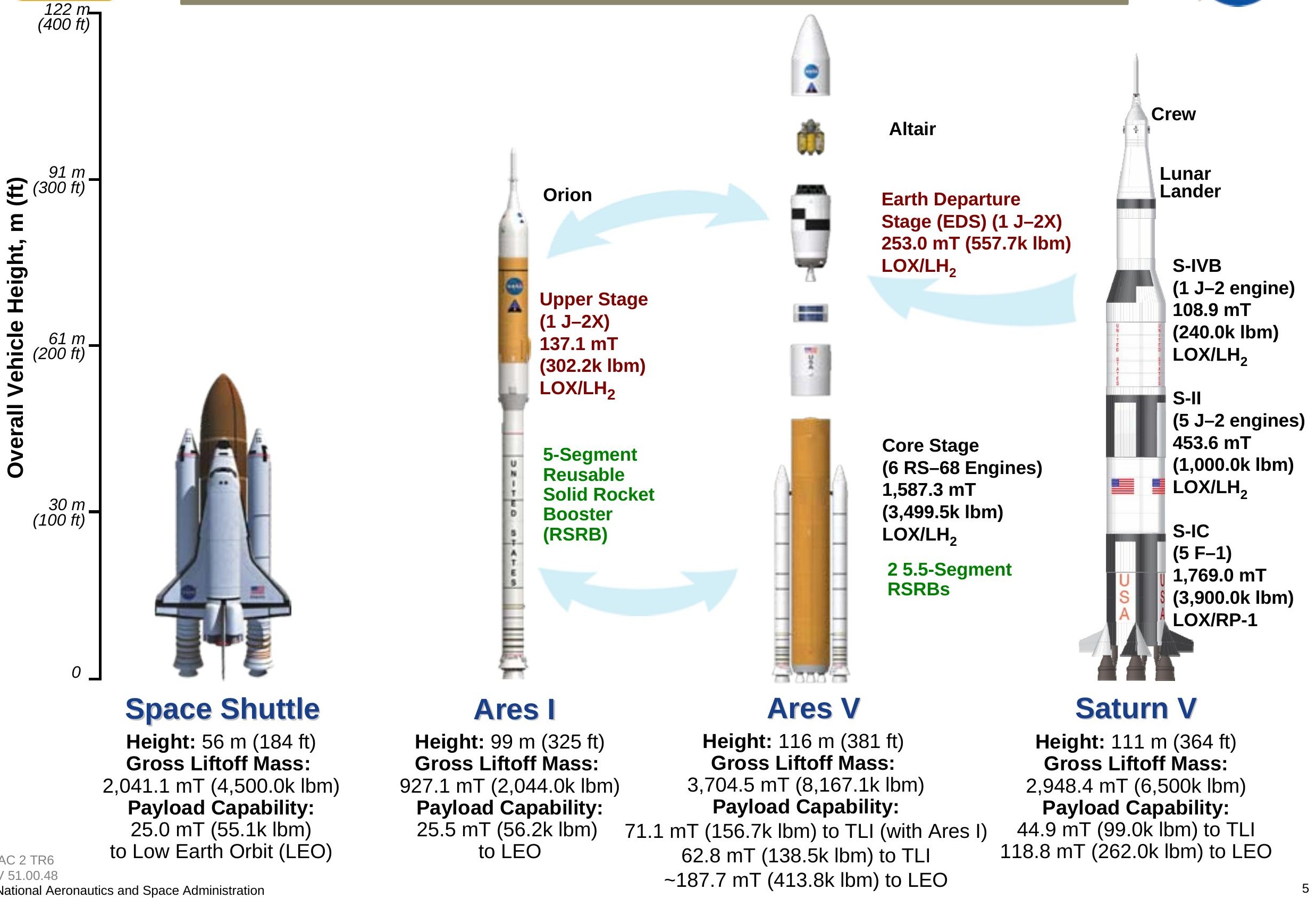




\section{Ares V Element Heritage}

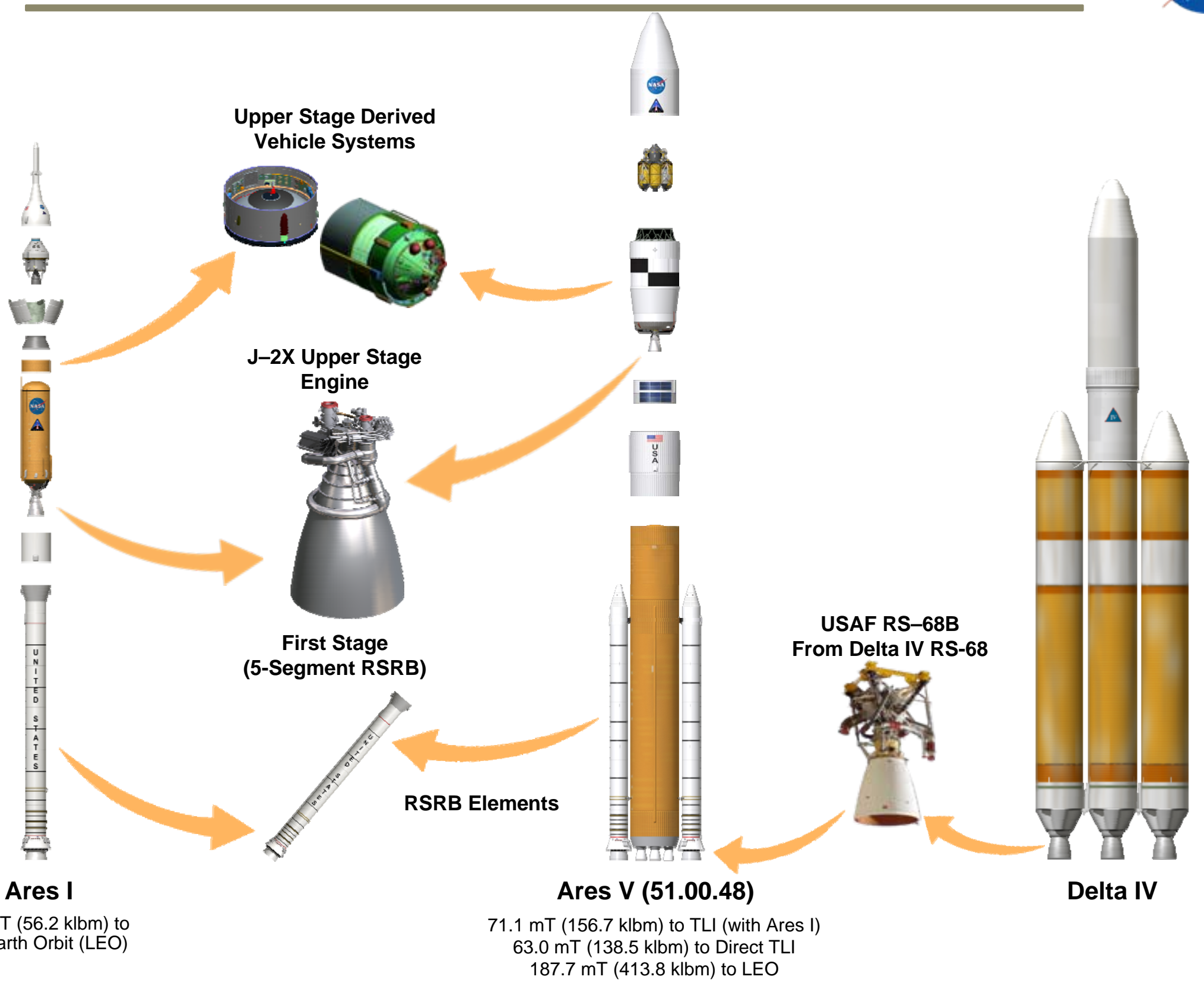




\section{From ESAS To Today}

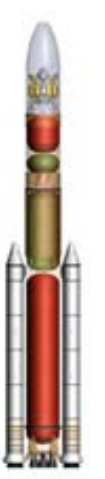

Original ESAS

Capability

- $8.4 \mathrm{~m} \mathrm{OML}$

- SSME Core

- 2 J2S EDS

- $45.0 \mathrm{mT}$ Lander

- 20.0 mT CEV

- No Loiter in

LEO

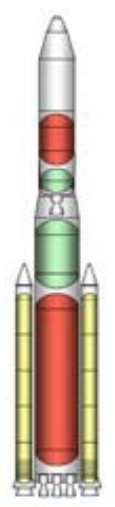

Change to RS-68B Core Engines

- Core dia: $8.4 \mathrm{~m}$ to

$10 m$

- Fvac: $490 k$ to $750 k$

- Isp: 452.1 to 414.7

sec

- Booster: HTPB to

PBAN propellant

(Ares I 53-06 thrust

trace)

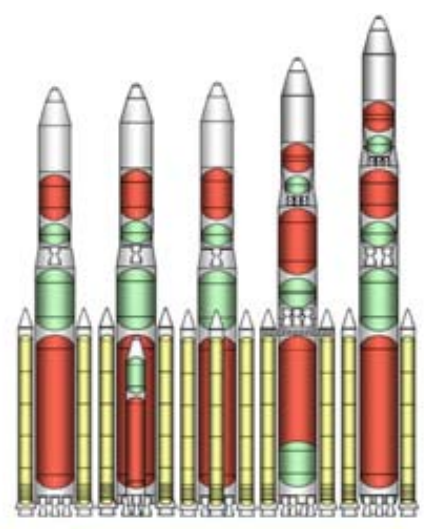

IDAC 3 Trade Space - SRM Propellant

- Stage Materials

- Extra Strapons

- Engine Type

- 10+ m dia. Core

- Number of Stages

- Shroud Material

- Shroud Size
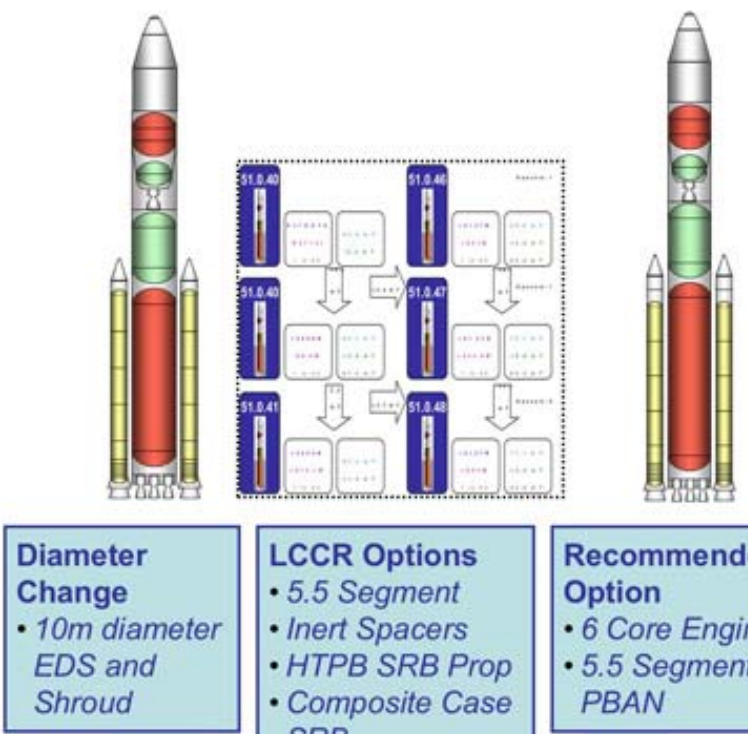

LCCR Options - 5.5 Segment

- Inert Spacers

- HTPB SRB Prop

- Composite Case

SRB

- 6 Engine Core
Recommended Option

- 6 Core Engines

- 5.5 Segment

PBAN
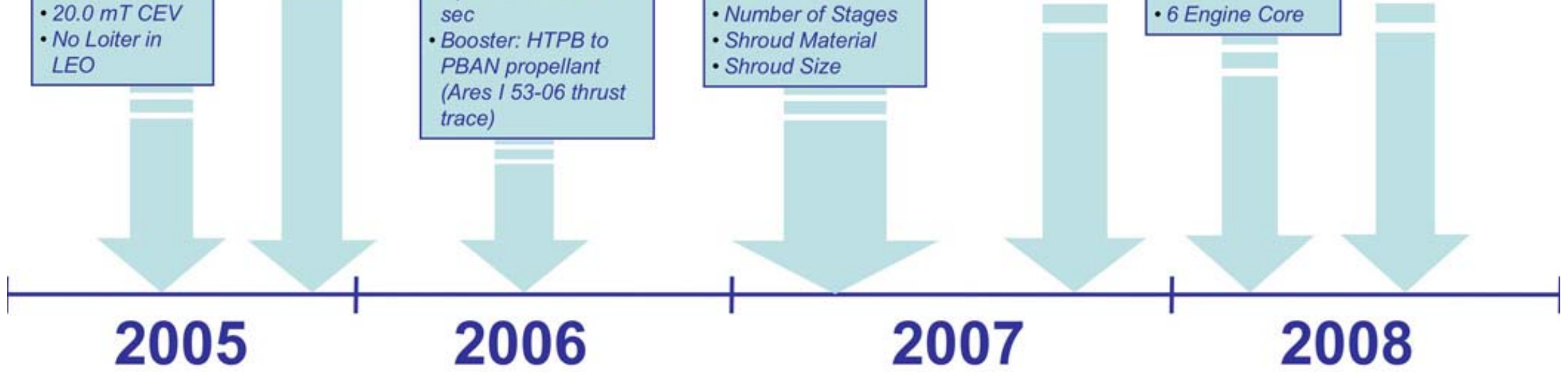

2008 


\section{Ares V (51.00.39) Elements}

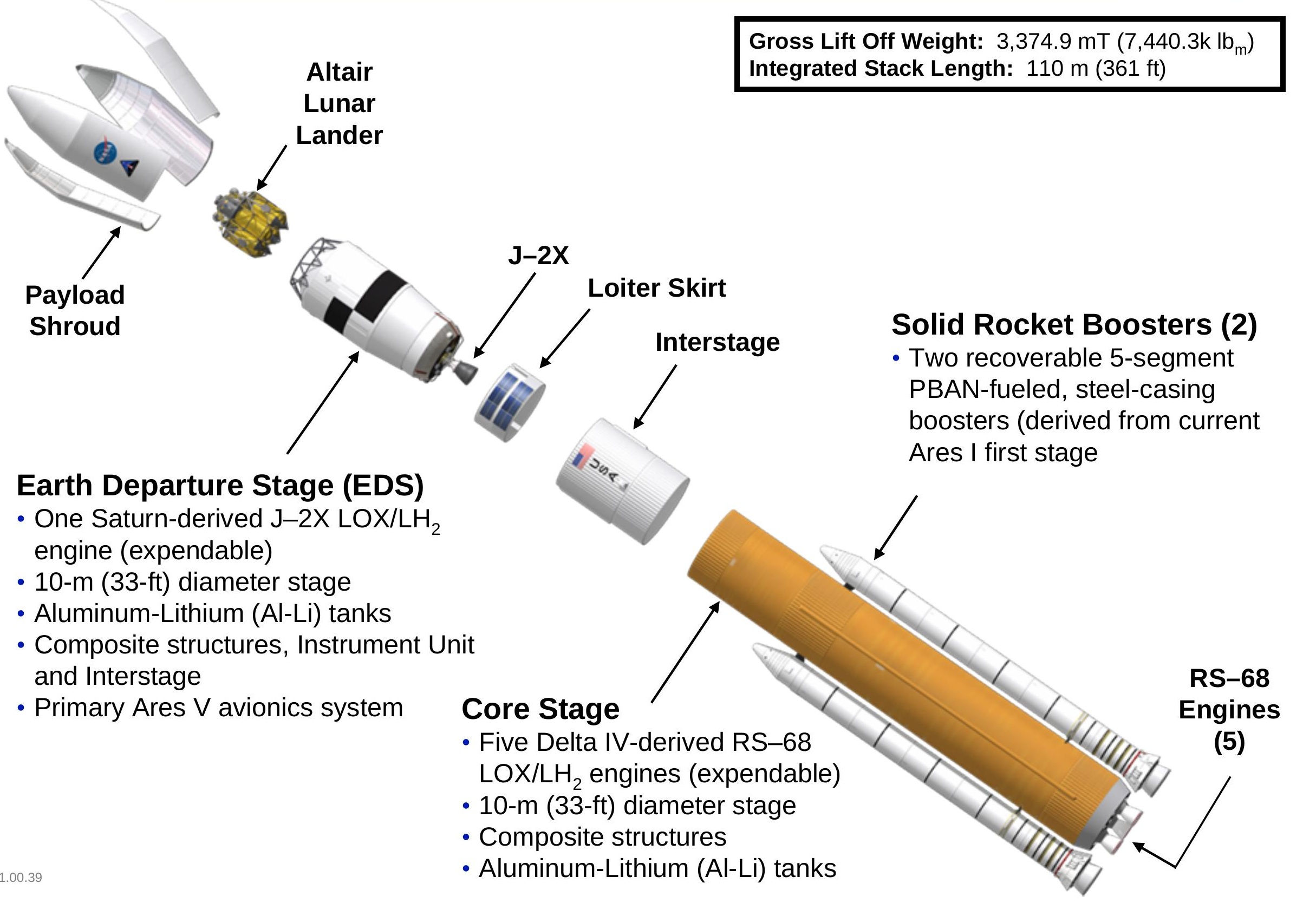




\section{The LCCR Tradespace}

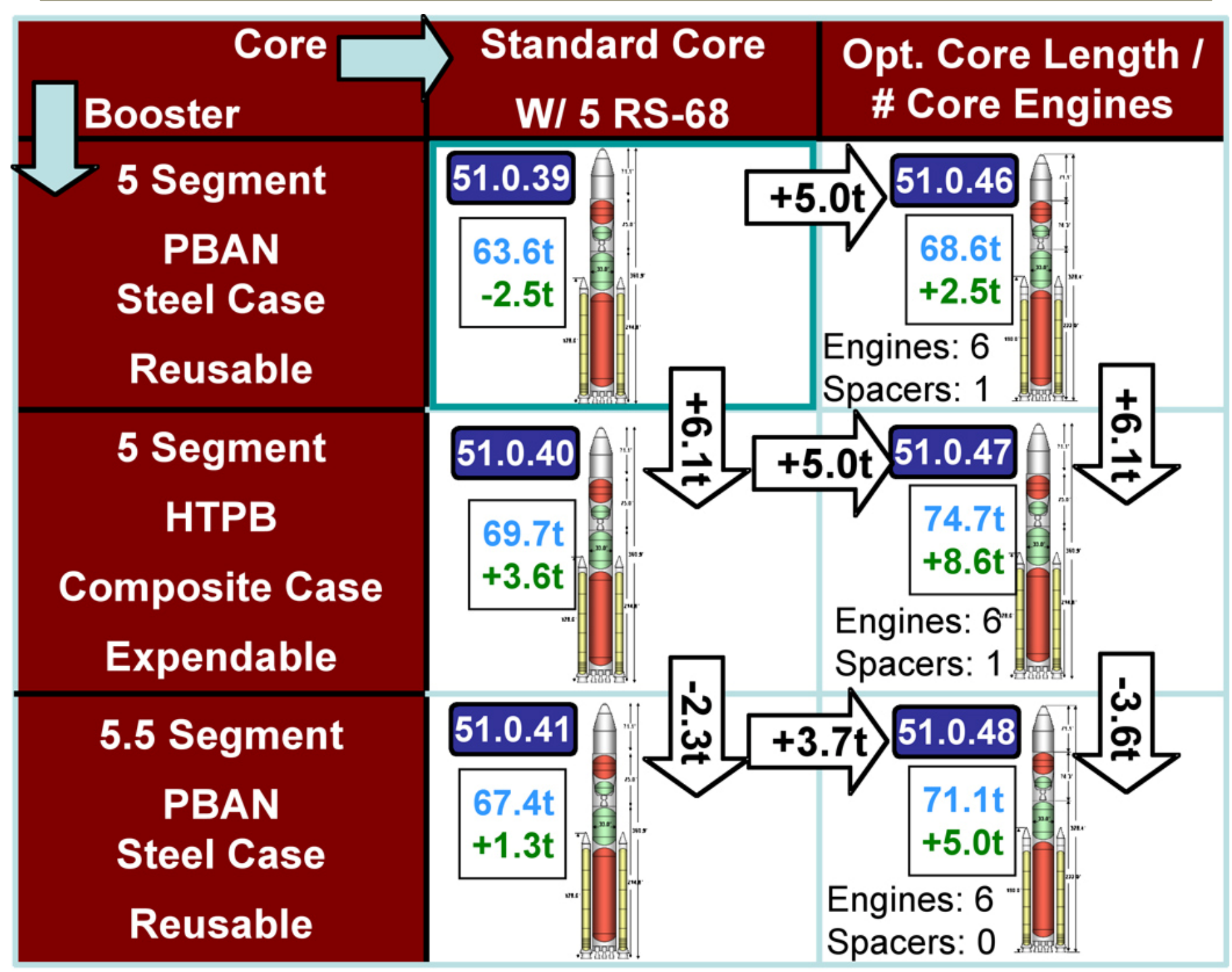

LCCR Study Reference 


\section{Ares V Elements Point of Departure Vehicle (51.00.48)}

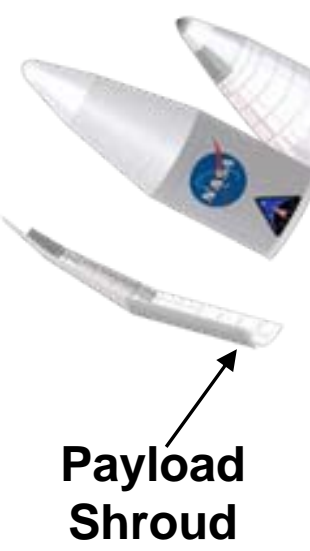

Gross Lift Off Mass: 3,704.5 mT (8,167.1k lbm)

Integrated Stack Length: $116 \mathrm{~m}(381 \mathrm{ft})$

Altair Lunar Lander

Earth Departure Stage (EDS)

- One Saturn-derived J-2X LOX/LH engine (expendable)

- 10-m (33-ft) diameter stage

- Aluminum-Lithium (Al-Li) tanks

- Composite structures, Instrument Unit and Interstage

- Primary Ares V avionics system

\section{Core Stage}

- Six Delta IV-derived RS-68B LOX/LH engines (expendable)

- 10-m (33-ft) diameter stage

- Composite structures

- Aluminum-Lithium (Al-Li) tanks
Solid Rocket Boosters (2)

- Two recoverable 5.5-segment PBAN-fueled, steel-casing boosters (derived from current Ares I first stage) 


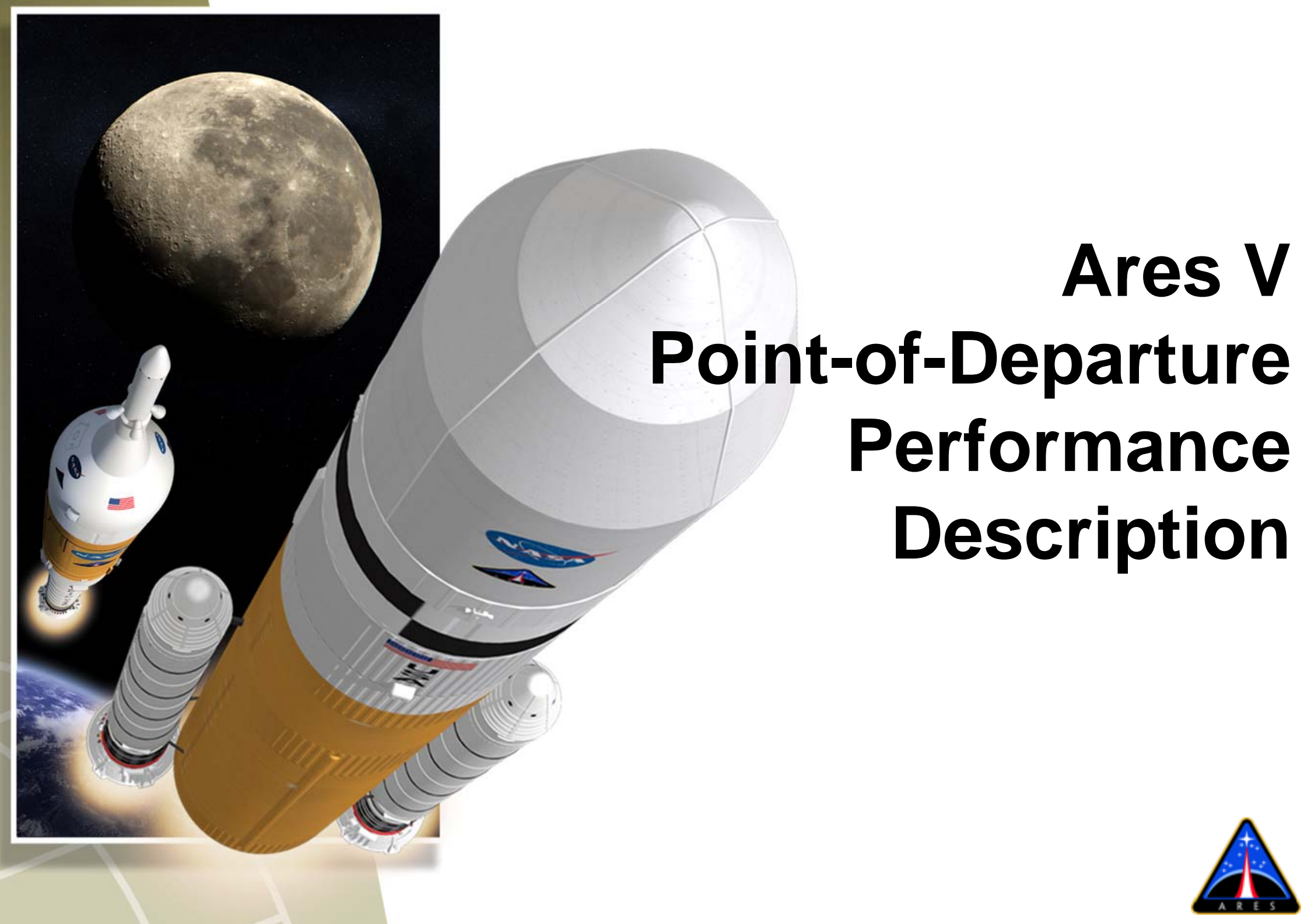




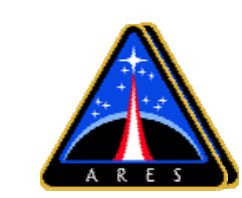

Ares V Profile for 1.5 Launch DRM

\subsubsection{Point Of Departure (Lunar Sortie)}

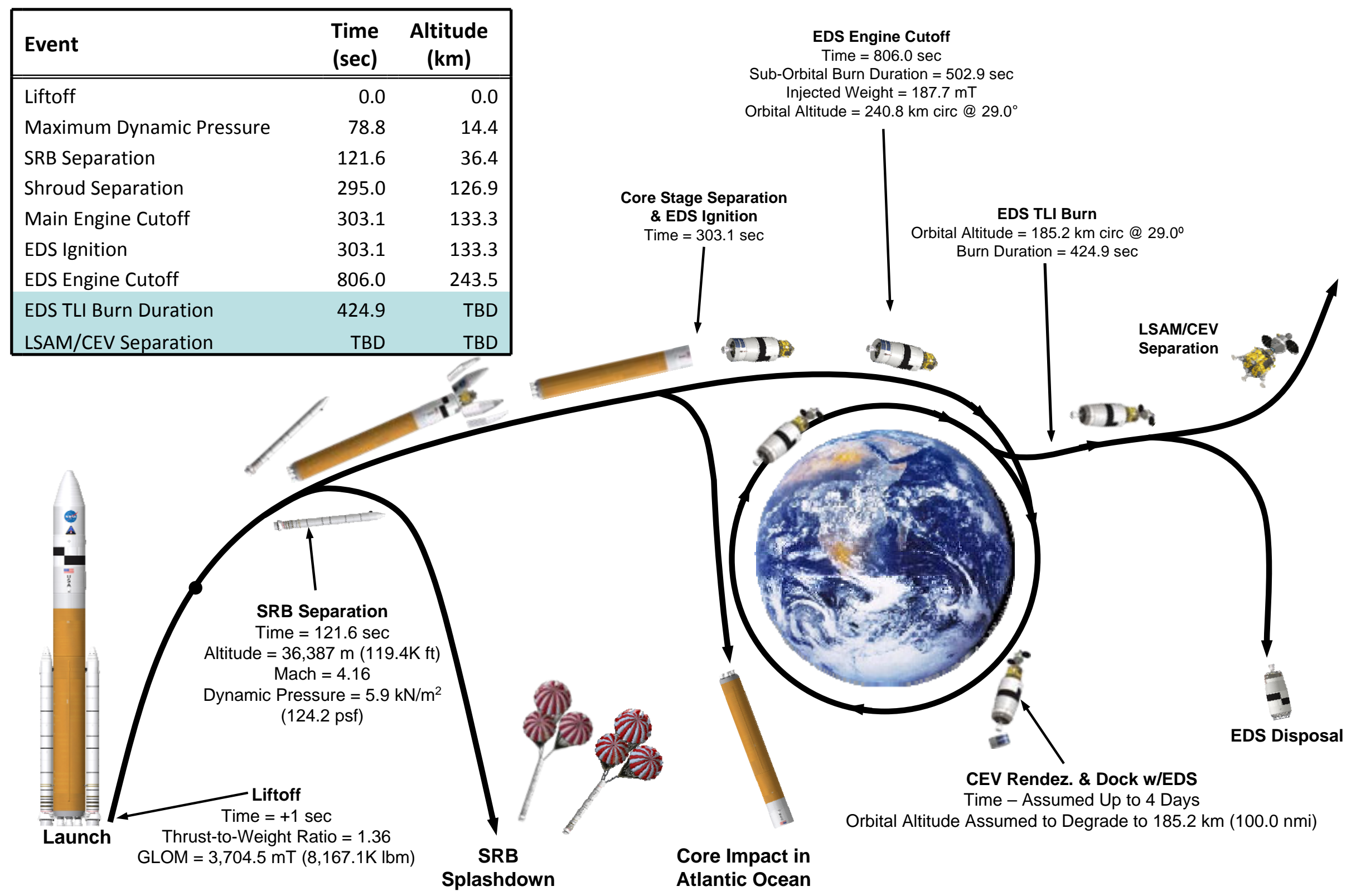




\section{Earth Departure Stage Design Concept Expanded View}

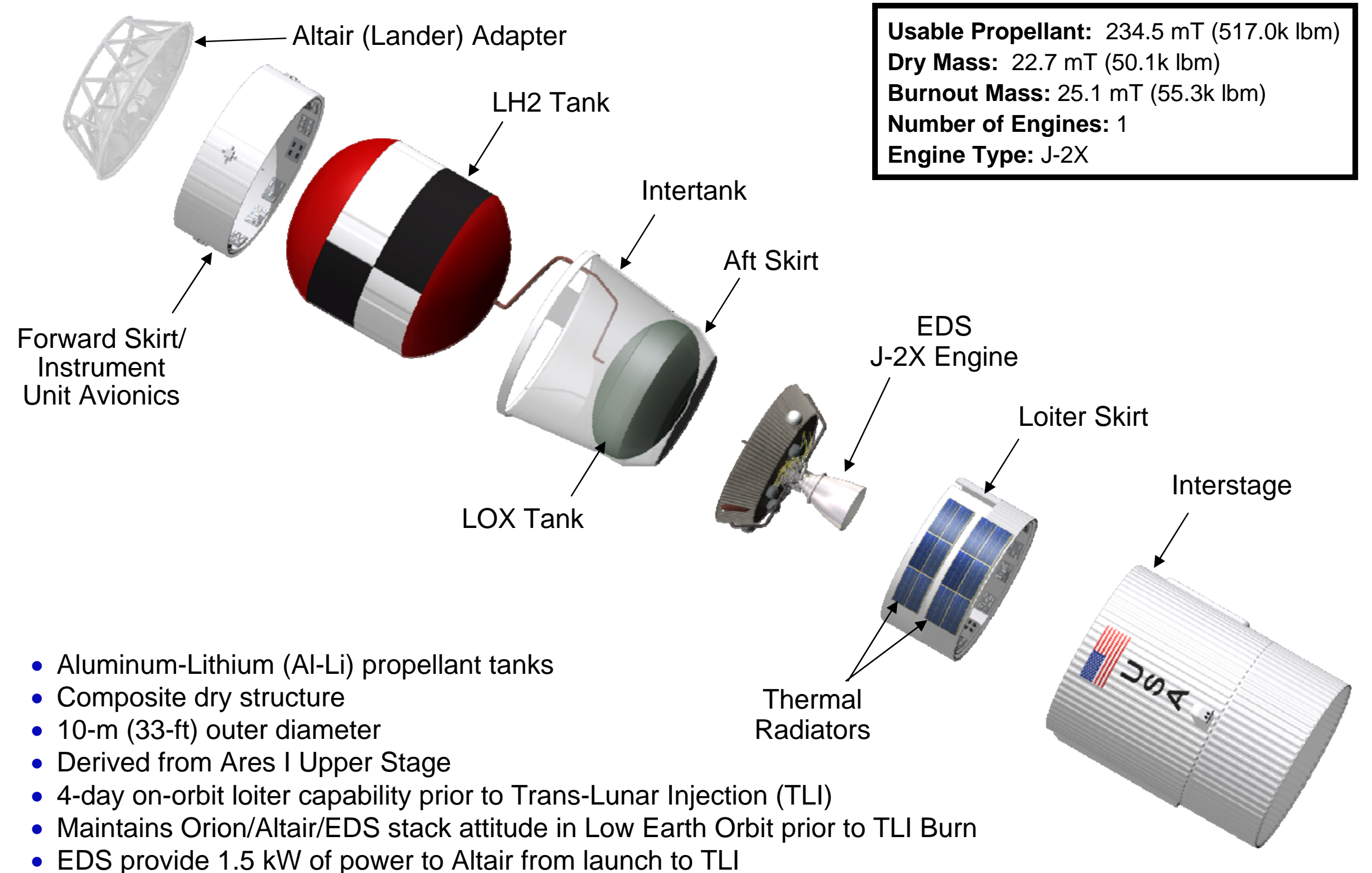

Usable Propellant: $234.5 \mathrm{mT}(517.0 \mathrm{k} \mathrm{lbm})$ Dry Mass: $22.7 \mathrm{mT}(50.1 \mathrm{k} \mathrm{lbm})$ Burnout Mass: $25.1 \mathrm{mT}$ (55.3k lbm) Number of Engines: 1

Engine Type: J-2X

Forward Skirt/ Instrument Unit Avionics

- Aluminum-Lithium (Al-Li) propellant tanks

- Composite dry structure

- 10-m (33-ft) outer diameter Radiators 


\section{Earth Departure Stage J-2X Engine}

Turbomachinery

- Based on J-2S MK-29 design

Gas Generator

- Based on
Engine Controller

- Based directly on RS-68 design and software architecture
Regeneratively Cooled Nozzle Section

- Based on long history of RS-27 success
Mass: $2.5 \mathrm{mT}$ (5.5k lbm)

Thrust: $1.3 \mathrm{M} \mathrm{N}$ (294.0k lbm) @ vac

Isp: 448 sec (vac)

Height: $4.7 \mathrm{~m}$ (185 in)

Diameter: 3.0 m (120 in)
Flexible Inlet Ducts

- Based on J-2 \& J-2S ducts

Open-Loop Pneumatic Control

- Similar to J-2

HIP-bonded MCC

- Based on RS-68

demonstrated technology

\section{Pratt \& Whitney \\ A United Technologies Company}

Pratt \& Whitney Rocketdyne 


\section{Core Stage Design Concept Expanded View}

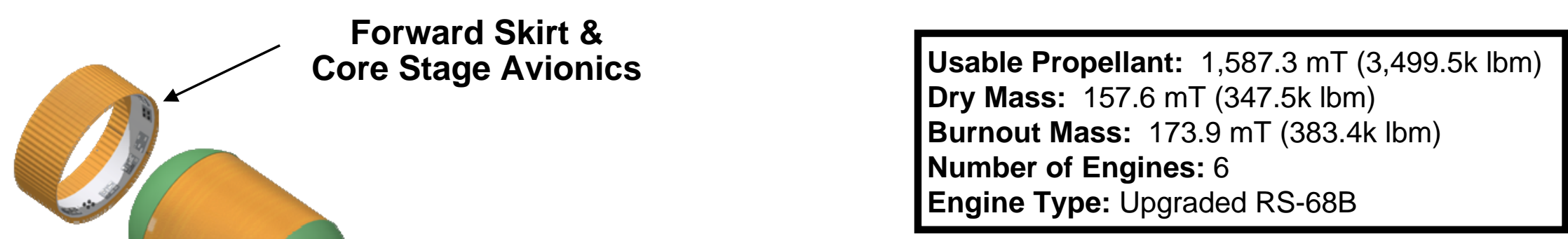

- Aluminum-Lithium (Al-Li) propellant tanks

- Composite dry structure

- 10-m (33-ft) outer diameter

Engine Thrust Structure

LH2 Tank \&

Systems Tunnel

LOX Tank

Intertank \& Thrust Beam
Dry Mass: $157.6 \mathrm{mT}$ (347.5k lbm)

Burnout Mass: $173.9 \mathrm{mT}(383.4 \mathrm{k} \mathrm{lbm})$

Engine Type: Upgraded RS-68B

\footnotetext{
- Derived from Shuttle External Tank
}

Engine Compartment 


\section{Core Stage Upgraded USAF RS-68B Engine}

* Redesigned turbine nozzles to increase maximum power level by $\approx 2 \%$

Redesigned turbine seals to significantly reduce helium usage for pre-launch

\section{Other RS-68A upgrades or} changes that may be included:

- Bearing material change

- New Gas Generator igniter design

- Improved Oxidizer Turbo Pump temp sensor

- Improved hot gas sensor

- 2nd stage Fuel Turbo Pump blisk crack mitigation

- Cavitation suppression

- ECU parts upgrade
Helium spin-start duct redesign, along with start sequence modifications, to help minimize preignition free hydrogen
* Higher element density main injector improving specific impulse and thrust Increased duration capability ablative nozzle

* RS-68A Upgrades 


\section{Ares V (51.00.48) Solid Rocket Booster (SRB)}

ATK

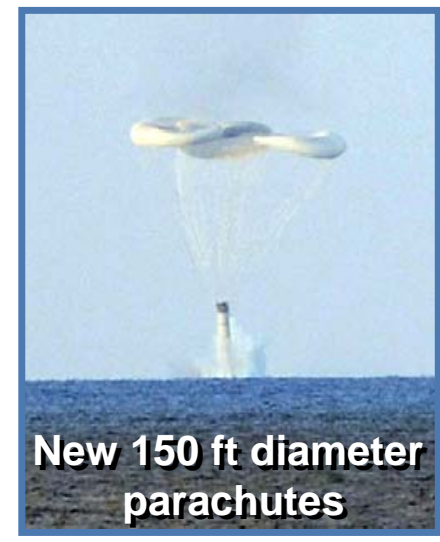

Mass: $794 \mathrm{mT}$ (1.8M lbm) Thrust: $15.8 \mathrm{M} \mathrm{N}$ (3.5M lbf)

Burn Duration: $126 \mathrm{sec}$

Height: $55 \mathrm{~m}(180 \mathrm{ft})$

Diameter: 3.7 m (12 ft)
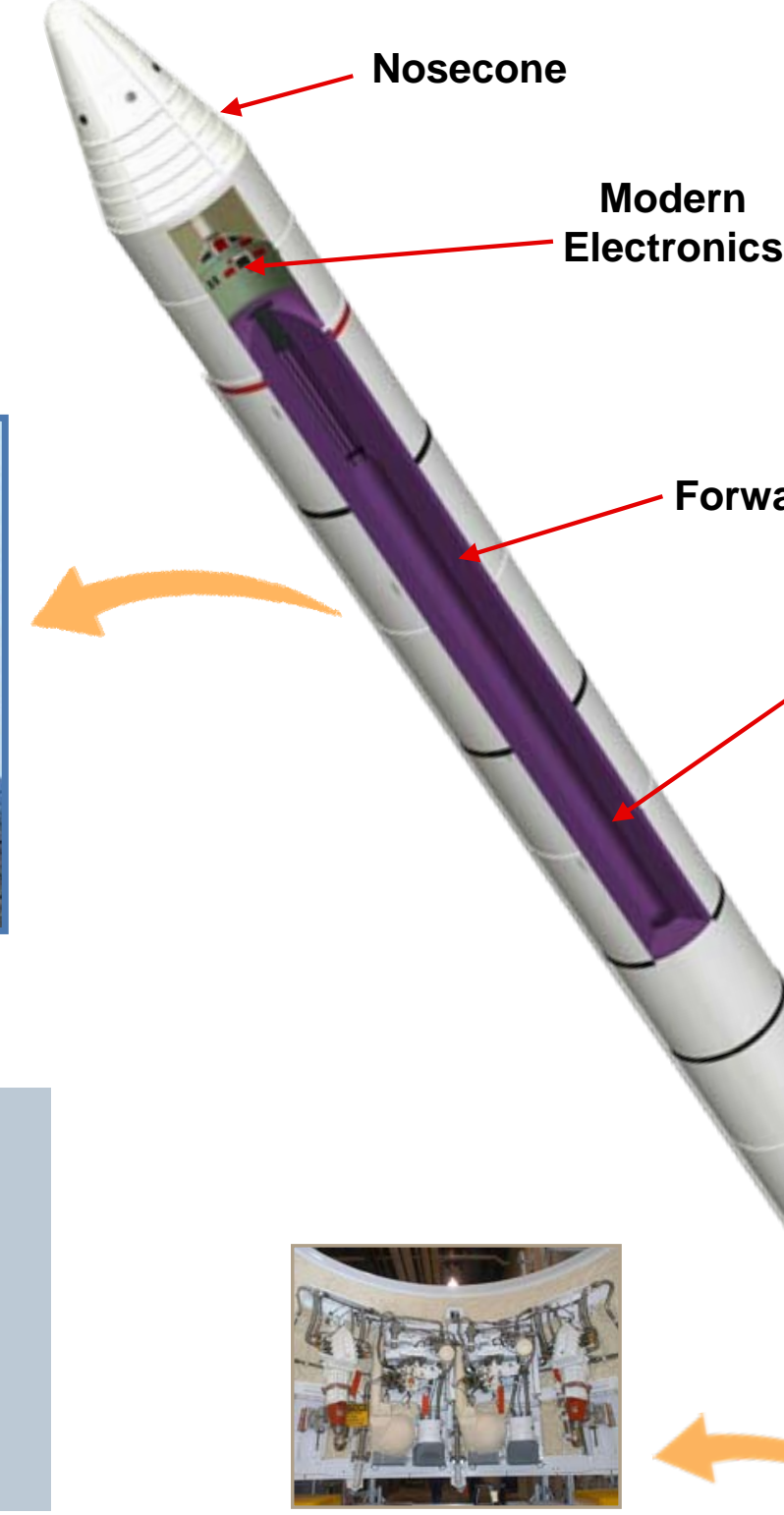

Electronics

Same Aft Skirt and Thrust Vector Control as Shuttle
Ares $V$ SRB is similar to Space Shuttle but optimized for lunar missions
12-Fin Forward Segment

Same propellant as Shuttle (PBAN)-Optimized for Ares Application

Same cases and joints as Shuttle 


\section{Payload Shroud Point Of Departure}

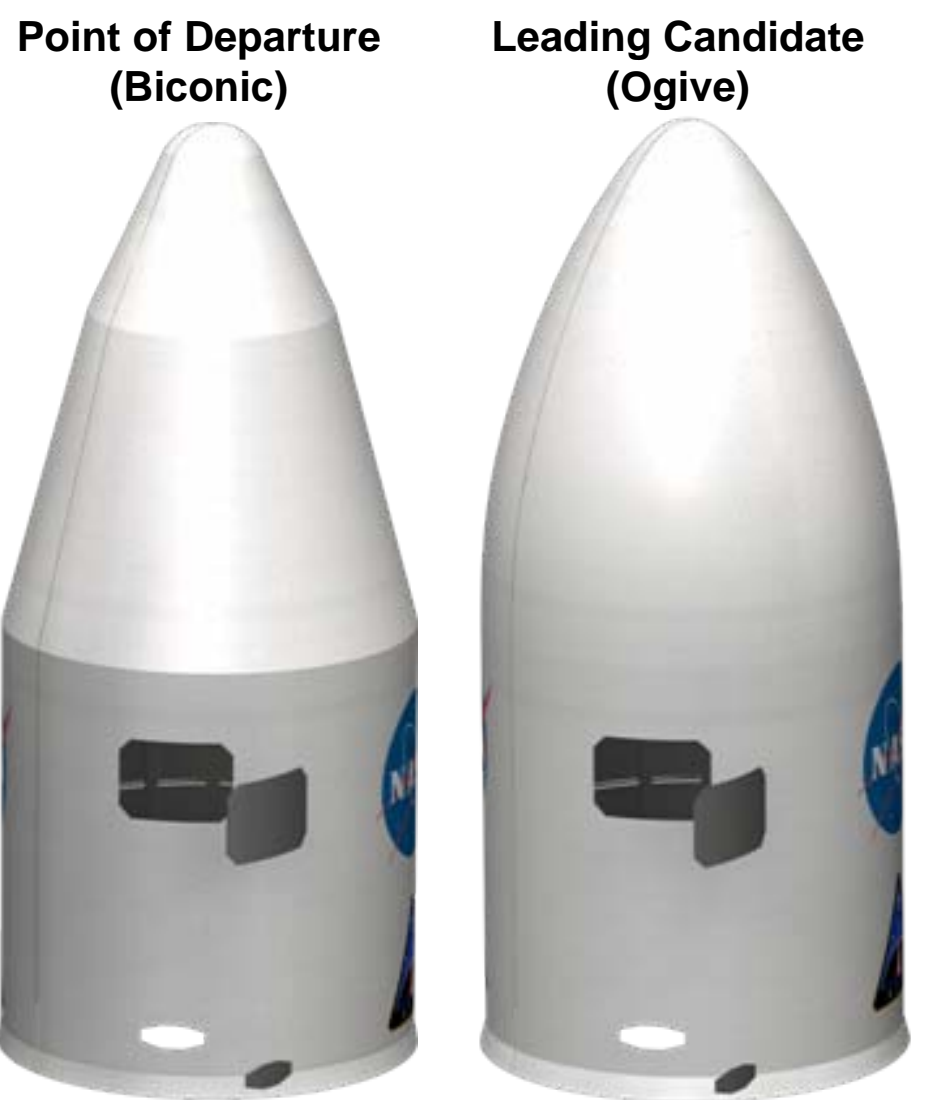

- Composite sandwich construction (CarbonEpoxy face sheets, Al honeycomb core)

- Painted cork TPS bonded to outer face sheet with RTV

- Payload access ports for maintenance, payload consumables and environmental control (while on ground)
Mass: $9.1 \mathrm{mT}$ (20.0k lbm) POD Geometry: Biconic Design: Quad sector Barrel Diameter: $10 \mathrm{~m}$ (33 ft) Barrel Length: $9.7 \mathrm{~m} \mathrm{(32 \textrm {ft } )}$ Total Length: $22 \mathrm{~m}$ (72ft)

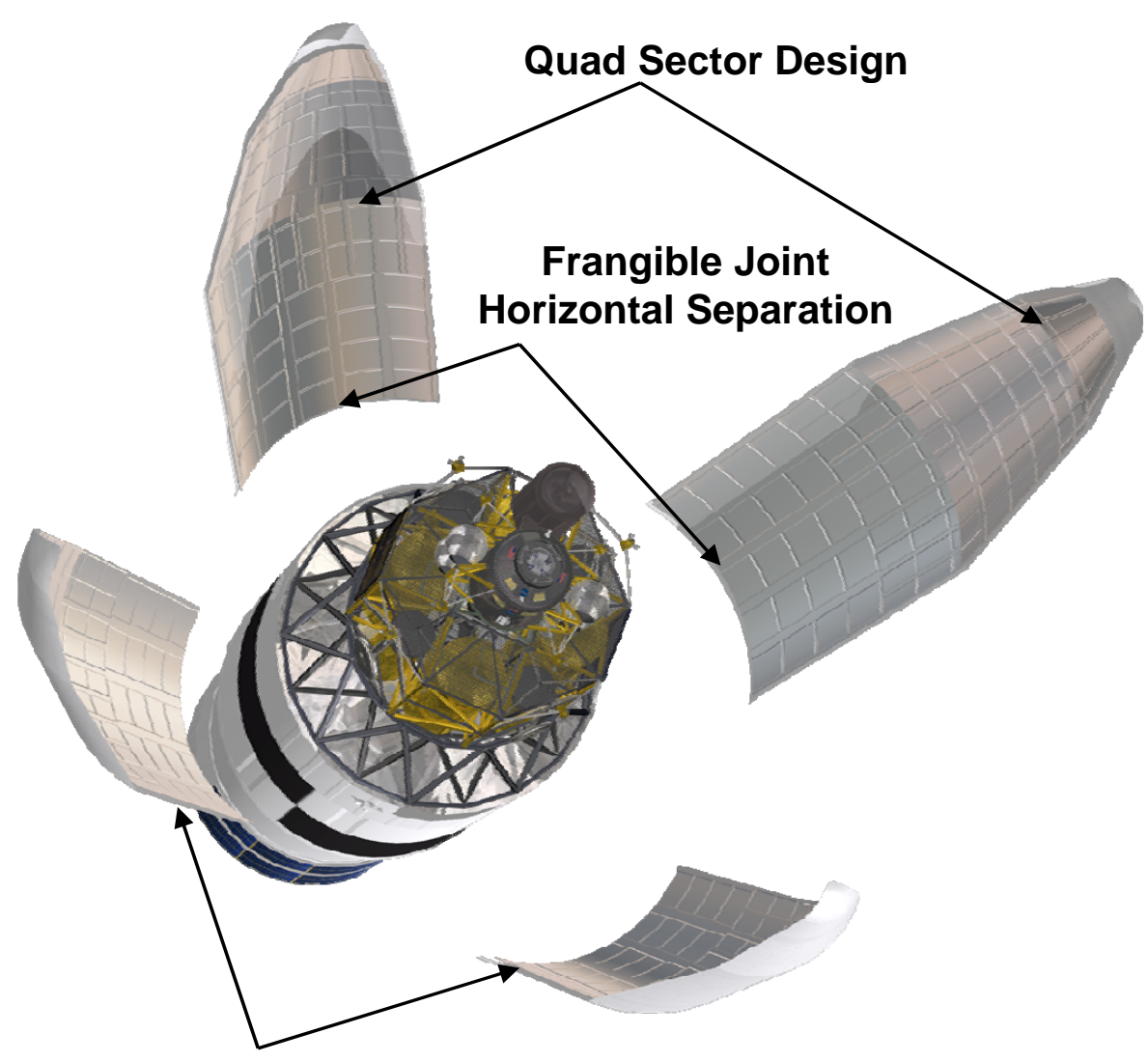

Thrust Rail Vertical Separation System Payload umbilical separation 


\section{Shroud Point Of Departure Dimensions}
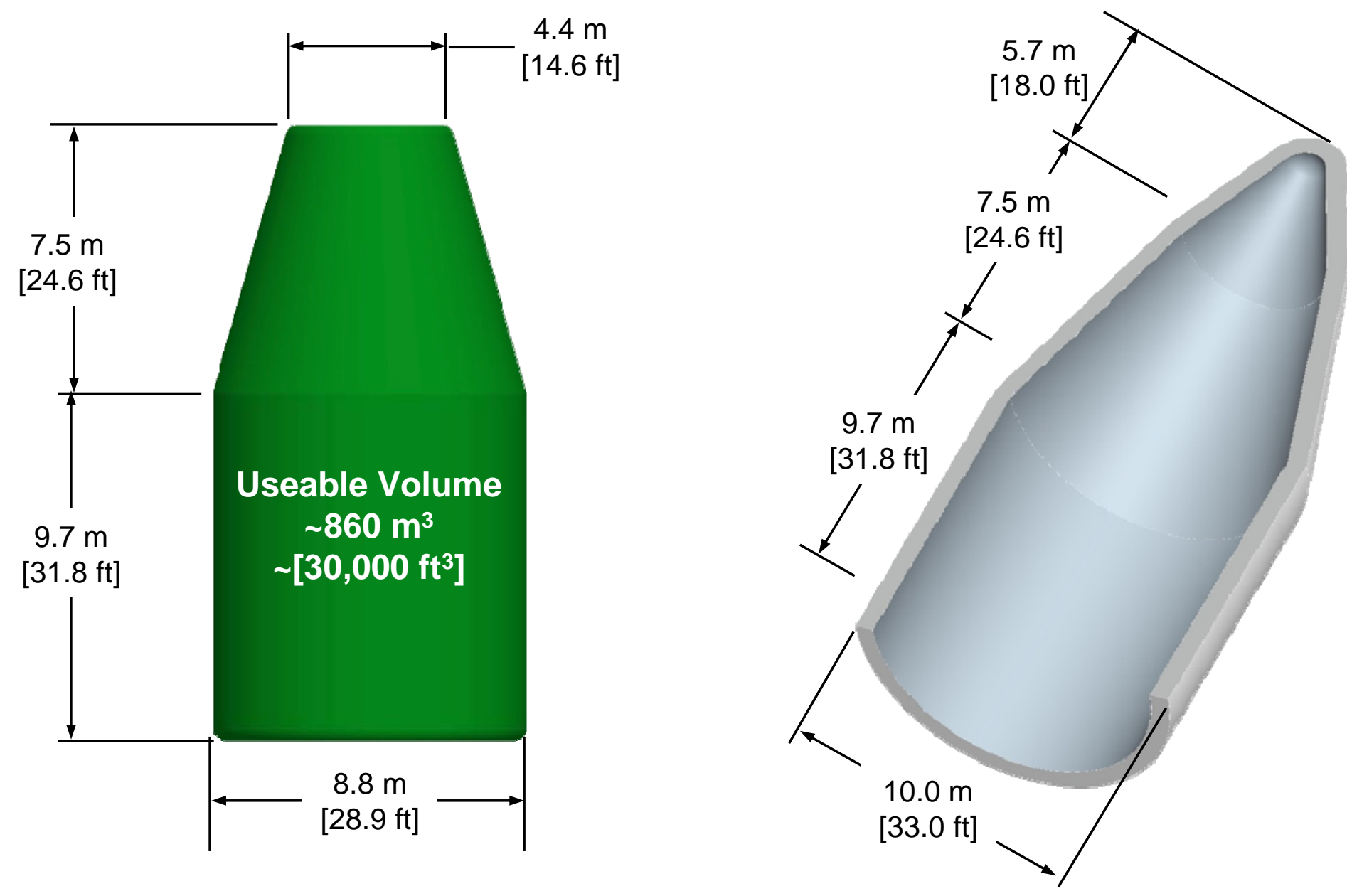


\section{Ares V Summary Schedule}

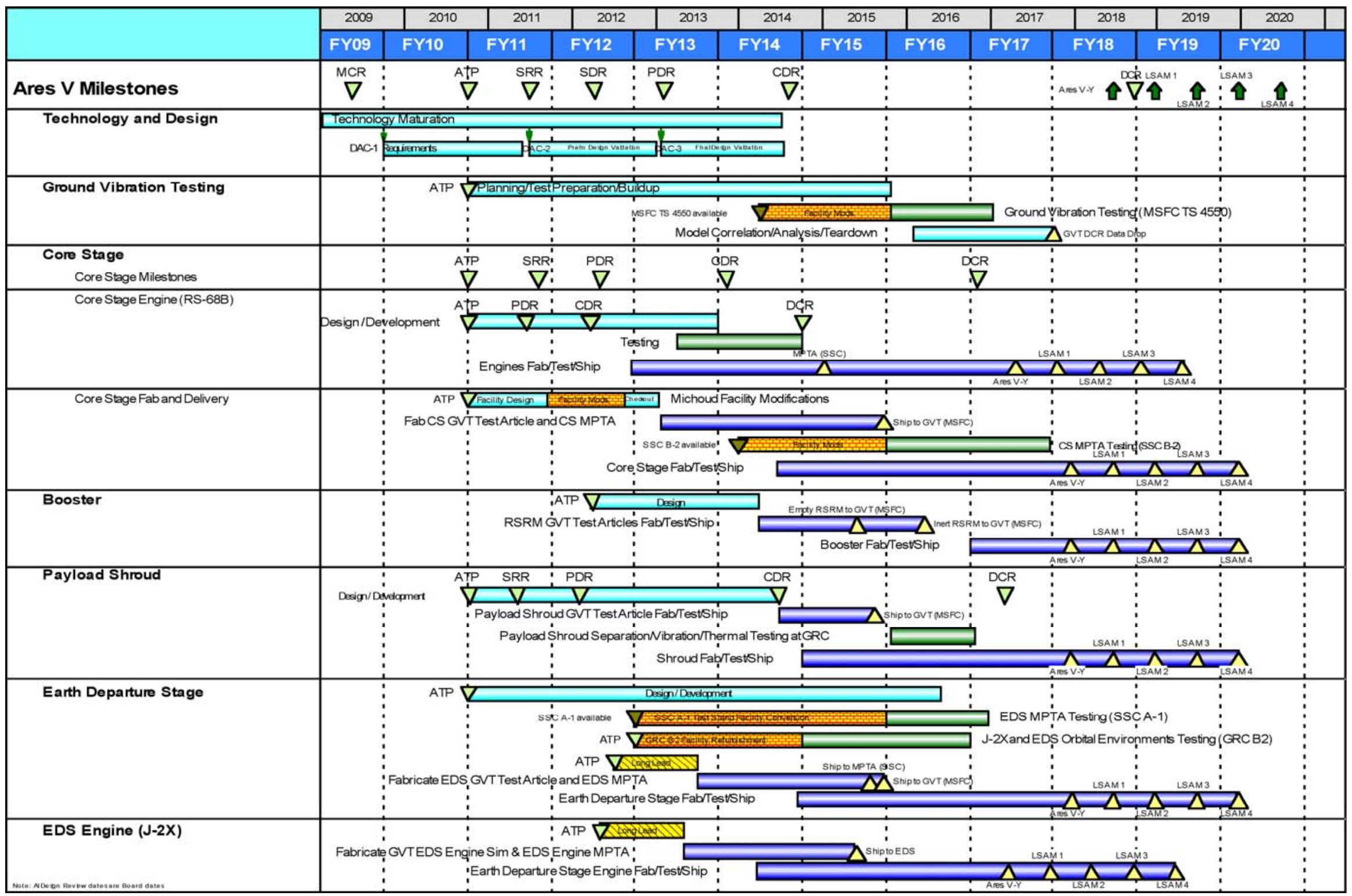




\section{Current Ares V Status}

- Ares V Initial 2008 Capability (51.00.48) exceeds Saturn Mass Capability by $\sim 30 \%$

- Ares V Lunar Capabilities Concept Review analysis focused on meeting lunar requirements and developing margin

- Ares V is sensitive to Loiter, Attitude, Power, and Altitude requirements in addition to payload performance

- Recommended new POD Ares V can meet current Human Lunar Return requirements with $\sim 6 \mathrm{mT}$ of Margin

- Utilizes 5.5 segment steel case PBAN Booster and 6-Engine Core

- Plan to maintain new composite HTPB booster as an option 